\title{
Implentation of a multiomodal approach to improve hand hygiene in a teaching hospital: change of paradigm
}

\author{
RE Quirós ${ }^{1 *}$, A Novau $^{1}$, L Fabbro ${ }^{1}$, G Desmery ${ }^{2}$ \\ From International Conference on Prevention \& Infection Control (ICPIC 2011) \\ Geneva, Switzerland. 29 June - 2 July 2011
}

\section{Introduction / objectives}

Many factors have been involved with low compliance of hand hygiene strategy such as the lack of resources and cultural barriers. In order to improve the level of adherence, a comprehensive program was implemented since Oct 09.

The aim of this study was to evaluate the impact of a multimodal approach to increase the compliance to hand hygiene among health personnel of our institution.

\section{Methods}

The program was based on the concept that "hand hygiene is everyone's commitment" (paradigm change). A multimodal strategy was implemented using WHO recommendations. Alcohol-gel was used as universal method for hand hygiene.Measurements of adherence were carried out identifying the 5 WHO's opportunities through five cross-sectional studies. The results of each study were shown through a graphic chart to each hospital area in comparison with the rest of institution. Data from Oct 09 were compared with those of Oct'10.

\section{Results}

A total of 4618 observations were performed. The overall adherence to hand hygiene increased from $46.3 \%$ to $59.9 \%$ (diff: $13.6 \%, 95 \%$ CI $7.7 \%$ to $19.5 \%$, p $<0.001)$. Stratified by type of professional, both nurses and doctors increased their level of adherence (52.1 vs $68.7 \%$ [diff: $16.6 \%, 95 \%$ CI $8.3 \%$ to $24.9 \%, p<0.001$ ], $41.6 \%$ vs $57.9 \%$ [diff: $16.3 \%$, $95 \%$ CI $6.6 \%$ to $26.0 \%$, p
$<0.01]$, respectively). Higher levels of adherence were observed in intensive care units $(77 \%)$ in comparison with general wards (38\%). The consumption of alcohol-gel increased from 49.9 liters per \%opt-days to 76.5 liters per \%opt-days (diff: $26.6 \%$, 95\% CI $18.4 \%$ to $34.7 \%$, p $<0.01$ ).

\section{Conclusion}

The implementation of a multimodal approach in our institution increased the adherence to hand hygiene among health personnel. The feed-back to each hospital area may have helped to raise the level of compliance.

\section{Disclosure of interest}

None declared.

\section{Author details}

'Prevention and Infection Control Department, Hospital Universitario Austral, Pilar, Argentina. ${ }^{2}$ Nursing School, Universidad Austral, Pilar, Argentina.

Published: 29 June 2011

doi:10.1186/1753-6561-5-S6-P254

Cite this article as: Quirós et al:: Implentation of a multiomodal approach to improve hand hygiene in a teaching hospital: change of paradigm. BMC Proceedings 2011 5(Suppl 6):P254. 